\section{Comparison of Clinical Performance of Supraglottic Airway Devices in Elderly Patients: A Prospective Randomized Trial}

\author{
Reyhan Polat $\odot$ \\ Sibel Çatalca $\odot$ \\ Julide Ergil $\odot$ \\ ilkay Baran $\odot$ \\ Aylin Tamam $\mathbb{0}$ \\ Yağmur Polat $\mathbb{0}$
}

Yaşlı Hastalarda Supraglottik Hava Yolu Gereçlerinin Klinik Performanslarının Karşılaştırılması: Prospektif Randomize Çalışma

\section{ABSTRACT}

Objective: Airway management in the elderly may be challenging. Supraglottic airway devices (SADS) may be used to provide airway security. The aim of study was to compare the efficacy and safety of different SADs, LMA classic (c-LMA), proseal LMA ( $p-L M A)$ and i-gel in anaesthetised and non-paralysed elderly patients.

Method: The study was approved by a local ethics committee. Eighty patients, aged older than 65 years, who were scheduled to undergo elective urological or orthopaedic surgery participated in the study. Each patient was randomly allocated into 1 of 3 groups: Group C: C-LMA $(n=26)$, Group P: $p$-LMA $(n=27)$ or Group I: i-gel $(n=27)$. The primary outcome was oropharyngeal sealing pressure (OSP). Secondary outcomes included the adequacy of positive pressure ventilation, ease of insertion, success rates, time to insertion, haemodynamic response and complications such as sore throat and dysphagia.

Results: There were no significant differences among the groups with respect to OSP ( $p=0.852)$, whereas there was a statistically significant difference between Group I and Group $C$ in terms of leak volume and leak fraction ( $p=0.042$ and $p=0.020$, respectively). Adverse events were similar among the groups ( $p>0.05$ ).

Conclusion: In this study, although the leak volume and leak fraction were lower in i-gel inserted patients, it was shown that i-gel, c-LMA and p-LMA provided adequate airway in elderly patients who were not applied muscle relaxants and will be operated under general anesthesia.

Keywords: I-gel, geriatric patient, laryngeal mask airway, oropharyngeal sealing pressure, proseal LMA

Öz

Amaç: Yaşlı hastalarda hava yolu yönetimi zor olabilir. Supraglottik hava yolu gereçleri hava yolu güvenliğini sağlamak için kullanılmaktadırlar. Bu çalıșmanın amacı, kas gevşetici uygulanmamıș, genel anestezi altında opere edilmesi planlanan yaşlı hastalarda farklı hava yolu gereçlerinin (klasik LMA (c-LMA), proseal LMA (p-LMA) ve i-gel) etkinliğini ve güvenilirliğini karşılaştırmaktır. Yöntem: Çalışma yerel bir etik kurul tarafından onaylandı. Elektif ürolojik veya ortopedik cerrahi geçirmesi planlanan 65 yaş üstü, 80 hasta çalıșmaya dahil edildi. Her hasta randomize olarak 3 gruptan birine dahil edildi: Grup C: c-LMA ( $n=26)$, Grup P: $p$-LMA ( $n=27)$ veya Grup I: i-gel ( $n=27)$. Çalıșmamızda birincil sonuç orofaringeal kaçak basıncı (OKB) idi. ikincil sonuçlar ise pozitif basınçIı ventilasyonunun yeterliliği, hava yolu gerecini yerleştirme kolaylığı ve başarı oranları, hava yolu gerecinin yerleştirilme süresi, hemodinamik değişiklikler, boğaz ağrısı ve disfaji gibi komplikasyonları içermekte idi.

Bulgular: Gruplar arasında OKB açısından anlamlı fark bulunmadı $(p=0.852)$, Grup I ve Grup C arasında kaçak hacmi ve kaçak fraksiyonu açısından istatistiksel olarak anlamlı fark vardı (sırasıyla $p=0.042$ ve $p=0.020)$. Yan etkiler gruplar arasında benzerdi $(p>0.05)$.

Sonuç: Bu çalışmada, i-gel yerleştirilen hastalarda kaçak hacmi ve kaçak fraksiyonu daha düşük olmakla birlikte i-gel, c-LMA ve p-LMA'nın kas gevşetici uygulanmamış ve genel anestezi altında opere edilecek yaşlı hastalarda yeterli hava yolu sağladığı gösterilmiştir.

Anahtar kelimeler: I-gel, yaşlı hasta, laringeal maske, orofaringeal kaçak basıncı, proseal LMA

\section{Received/Geliş: 10 June 2020 Accepted/Kabul: 04 November 2020 Publication date: 29 January 2021}

Cite as: Polat R, Çatalca S, Ergil J, Baran I, Tamam A, Polat Y. Comparison of clinical performance of supraglottic airway devices in elderly patients: A prospective randomized trial. JARSS 2021;29(1):9-17.

Reyhan Polat

Sağlık Bilimleri Üniversitesi, Dışkapı Yıldırım Beyazıt Eğitim ve Araştrrma Hastanesi, Anesteziyoloji ve Reanimasyon Kliniği, Ankara, Türkiye reyhanp9@gmail.com ORCID: 0000-0003-3318-1330

S. Çatalca 0000-0002-8899-1106

J. Ergil 0000-0002-4580-7866

i. Baran 0000-0001-9355-5950

A. Tamam 0000-0001-7210-2047

Sağlık Bilimleri Üniversitesi,

Dışkapı Yıldırım Beyazıt Eğitim ve Araştırma Hastanesi, Anesteziyoloji ve Reanimasyon Kliniği, Ankara, Türkiye

Y. Polat 0000-0002-1953-2512 Yıldırım Beyazıt Üniversitesi, Biyoistatistik Anabilim Dall, Ankara, Türkiye 


\section{INTRODUCTION}

Supraglottic Airway Devices (SADs) are designed as an alternative to endotracheal tube and mask ventilation to provide an airway for ventilation, oxygenation and administration of anaesthetic gases. Laryngeal mask airway classicTM (c-LMA), is a minimally invasive first-generation SAD. Compared to the endotracheal tube, placement of the c-LMA is easier and quicker, requires lower concentration of anaesthetics and has a lower risk of causing sore throat. However, it has lower sealing pressures and is associated with a higher incidence of gastric insufflation (1). Second generation SADs, such as i-gel (Intersurgical, Wokingham, UK) and proseal LMA (p-LMA) (The Laryngeal Mask Company, Ltd, Wooburn Green Bucks, UK), were produced to overcome the perceived shortcomings of the c-LMA, such as lack of protection against aspiration and a low sealing pressure ${ }^{(2)}$. The clinical performance of SADs has been evaluated in many studies ${ }^{(3-5)}$. However, most of the studies have been performed in surgical patients of different age groups and the performance of these devices when used for the elderly patients, is not well known.

Many elderly patients with comorbid diseases will need airway management during the course of their illness. There are many anatomic, physiopathological and cognitive changes that occur in the elderly patients compared to younger patients and age may have a significant influence on the efficacy and safety of SADs ${ }^{(6)}$. In fact, clinical performance of SADs in general has been reported to be lower in the elderly than in young adults ${ }^{(5)}$. We hypothesised that i-gel would better adapt to the anatomical changes in the geriatric patients due to its thermoelastic structure and would provide higher oropharyngeal sealing pressure (OSP). In this study, we planned to compare the clinical performance of these devices, i-gel, p-LMA and c-LMA, in patients aged older than 65 years.

\section{MATERIAL and METHODS}

The study was conducted once the local ethical commitee permission was received (11.06.2018-51/20). The study was prospectively registered at the Australian New Zealand Clinical Trials Registry
(ACTRN12618001473257) and was conducted in compliance with the CONSORT guidelines and the Helsinki Declaration between February and April of 2019. Written informed consent was obtained from participating patients older than 65 years of age with American Society of Anesthesiologists (ASA) scores of I-III, who were scheduled for elective urological and orthopaedical surgery. Every precaution was taken for the protection of patients.

Patients were excluded from the study if they met one or more of the following criteria: High risk of regurgitation or aspiration (e.g. gastro-oesophageal reflux, hiatus hernia), or pulmonary diseases (e.g. asthma, pneumonia), recent upper respiratory infection, ASA physical status of $>$ III, refusal to participate in the study or failed third-attempt of SGA placement.

Demographic variables of age, sex, body mass index (BMI), ASA physical status were recorded. Anatomic parameters relevant to airway management, such as modified Mallampati score, thyromental distance, inter-incisor distance, upper lip bite test, measurement of neck circumference presence of a beard and condition of teeth were also recorded during their preoperative visit.

All patients fasted for at least 6 hours prior to beginning of the study and none of the patients received any premedication. Patients were monitored by electrocardiogram, pulse oximeter, and noninvasive blood pressure monitor. To ensure intravenous hydration and medication, an intravenous line was secured on the dorsum of the left hand.

Each patient was randomised into one of the following three groups; group $C$ (c-LMA), group $P(p-L M A)$ or group I (i-gel) using a sealed envelope. In order to avoid any bias, the trained researcher picked the device to insert from sealed and opaque envelopes to conceal the group allocations.

Preoxygenation was carried out with $100 \%$ oxygen with tidal volume ventilation for 3 minutes. Induction was achieved with intravenous fentanyl $1-1.5 \mathrm{mcg}$ $\mathrm{kg}^{-1}$, lidocaine $0.5-1 \mathrm{mg} \mathrm{kg}^{-1}$ and propofol $1.5-2 \mathrm{mg}$ $\mathrm{kg}^{-1}$. SADs were lubricated with a water-soluble gel and all insertions were performed with a standardised technique according to the manufacturers' 
instructions when the patients' jaws were sufficiently loose. The size of SADs was chosen according to the patient's weight and the manufacturer's recommendation. SAD cuffs that required inflation were inflated up to $55-60 \mathrm{~cm} \mathrm{H}_{2} \mathrm{O}$ using a cuff manometer (VBM Medizinchnik, GmbH, Germany). Effective ventilation was tested by observing chest wall movements and 5 consecutive capnography curves on the monitor.

Patients were ventilated with a tidal volume of $7 \mathrm{~mL}$ $\mathrm{kg}^{-1}$ and at a rate of $10-15$ breaths $\mathrm{min}^{-1}$ to maintain $\mathrm{ETCO}_{2}$ at 35-40 mmHg. Oropharyngeal sealing pressure was measured by closing the anaesthetic circuit to the atmosphere. Ventilation was stopped momentarily and the patient was supplied with a fresh gas flow of $3 \mathrm{~L} \mathrm{~min}$. The pressure in the airway circuit was recorded until an audible leak occurred or airway pressure plateaued ${ }^{(7)}$. For safety concerns, the maximal allowable OSP was determined to be 30 $\mathrm{cmH}_{2} \mathrm{O}$. The detected OSP measurements constitute the primary outcome of this study. The leak volume was calculated by taking the difference between the set tidal volume and the expired volume. The leakage fraction was calculated by dividing the leak volume to the set tidal volume. The peak inspiratory pressures (PIPs) were also noted.

We recorded the number of insertion attempts required to achieve acceptable sealing and insertion time (time to establish effective ventilation), which was defined as the duration between picking up the prepared device and obtaining the first capnograph trace. Acceptable sealing was defined as the leak fraction at $<0.02$ and the PIP $\leq 30 \mathrm{cmH}_{2} \mathrm{O}$. If effective ventilation was not achieved after initial insertion, the device was completely removed to prepare for another insertion attempt. If insertion was unsuccessful after two attempts, a third attempt was made with a different size of the same SAD. The decision to up or down size the SAD was made by the attending anaesthesiologist, based on clinical judgement ${ }^{(9)}$.

Anesthesia was maintained with $1.5-2 \%$ sevoflurane in the oxygen-air (50-50\%) mixture. For perioperative analgesia, $0.05-0.1 \mathrm{mcg} \mathrm{kg}^{-1} \mathrm{~min}^{-1}$ remifentanil infusion was used. At the end of surgery, sevoflurane and remifentanil infusion was terminated and the
SAD's were removed after the patients opened their eyes and obeyed commands.

Mean arteriel pressure (MAP) and heart rate (HR) were noted before and just after induction and in intervals of 1-3-5 minutes following the insertion of SAD. During emergence, occurrences of desaturation $\left(\mathrm{SPO}_{2} \leq 90 \%\right.$ for more than $10 \mathrm{sn}$ ), aspiration, coughing regurgitation and laryngospasm were recorded. The airway device was then inspected for visible blood. All patients were observed for $1 \mathrm{~h}$ in the postanesthesia care unit for adverse events, such as sore throat or dysphagia by an independent observer.

Oropharyngeal sealing pressure was assessed as the primary outcome and the adequacy of positive pressure ventilation, ease of insertion, time to insertion, success rates, haemodynamic response and complications were also evaluated.

\section{Statistical analysis}

Our primary outcome was OSP. Previously, no study compared all three devices in one setting. Hence, we calculated the sample size based on the pilot study with mean difference of OSP as $8 \mathrm{cmH}_{2} \mathrm{O}$ between i-gel and p-LMA. The sample size came out to be 26 patients in each group at a power of $95 \%$ and alpha error of 0.05 . Considering the possibility of dropouts from the study, we decided to include 82 patients.

The suitability of continuous variables such as age, $\mathrm{BMI}$, duration of surgery and duration of anesthesia to the normal distribution in the study was examined by Shapiro Wilk's test and graphical methods. Variables matching normal distribution were mean \pm standart deviations [mean \pm sd] and nonmatching variables are summarized by median (min; max) [median (min; max)]. Frequency and percentage [n (\%)] were used to summarize categorical variables such as gender, ASA, beard.

The ANOVA test (ANalysis of VArience) was used for the comparison of the age variable according to the groups. Kruskal Wallis test was used where normality and variance homogeneity assumptions such as neck circumference, mouth opening, thyromental distance were not provided. Where statistical differences were determined, the post-hoc Mann Whitney $\mathrm{U}$ test with Bonferroni correction was reported to 
determine where the difference stems from.

The repeated measurements of the mean arterial pressure and heart rate were compared by Friedman test within each group. Bonferroni correction was applied for pairwise comparisons of repeated measurements when necessary.

Chi-square test was used to compare categorical variables such as gender, ASA, Mallampati score, blood-stained SAD according to the groups and Fisher-Freeman-Halton test and Pearson Chi-Square test results were reported as appropriate. Where a significant difference was determined in " $\mathrm{R} \times \mathrm{C}$ " type tables, a special post-hoc chi-square code written in RStudio program was used to determine where the difference originates.

Statistical significance level was determined as $p$ $<0.05$. Statistical analyzes were performed using IBM SPSS Statistics 25.0 (IBM Corp. Released 2017. IBM SPSS Statistics for Windows, Version 25.0. Armonk, NY: IBM Corp.) and MS-Excel 2016; RStudio (RStudio Team 2015). RStudio: Integrated Development for R. RStudio, Inc., Boston, MA URL http://www.rstudio. $\mathrm{com} /$ ) was used for the chi-square post-hoc tests.

\section{RESULTS}

Eighty-four patients who qualified for eligibility were randomised into c-LMA, $p$-LMA and i-gel groups. Two patient from the c-LMA group, one patient from the

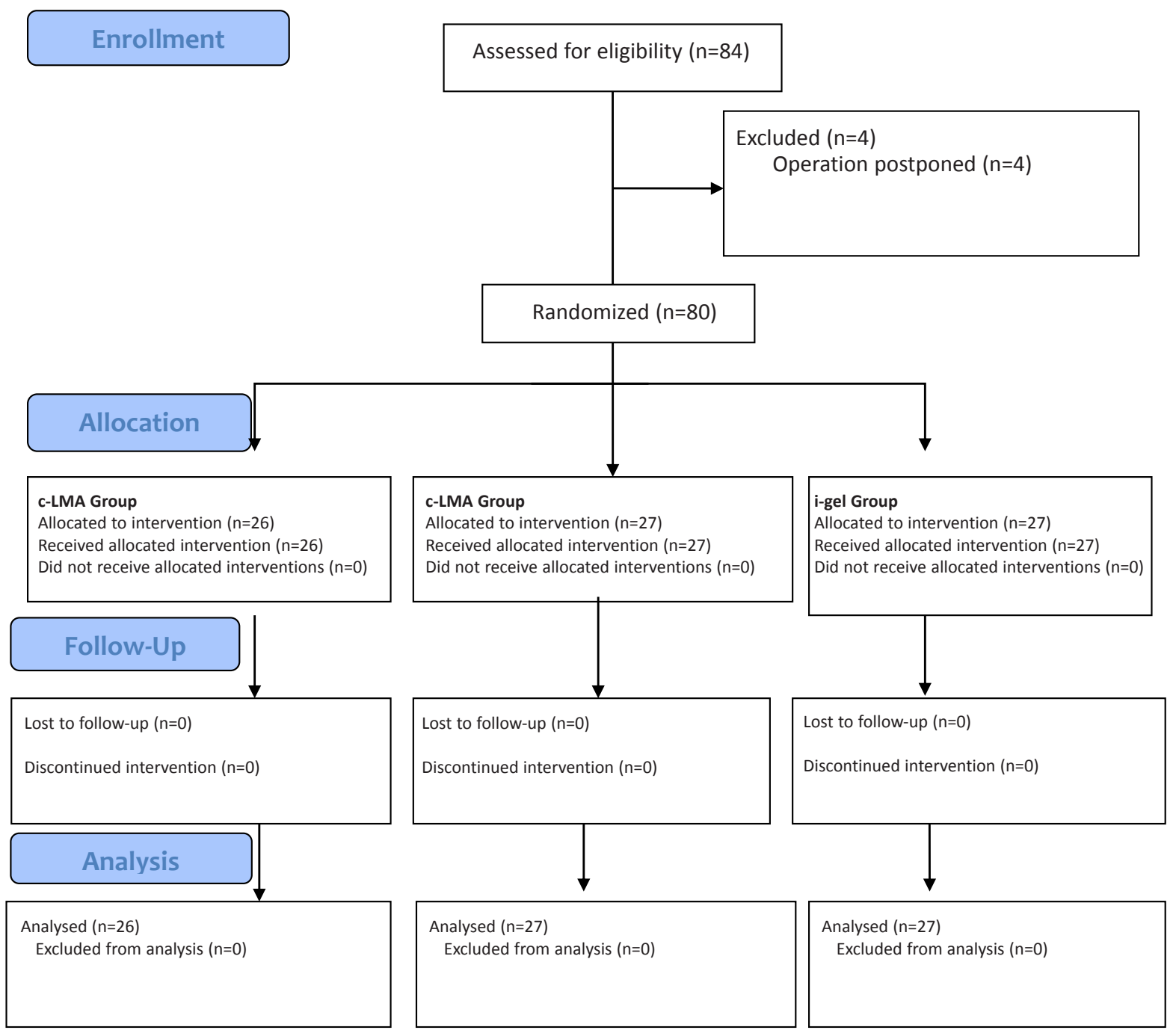

Figure 1. 
l-gel group and one patient from the p-LMA group wanted to postpone their surgical procedures to future dates; details and complications relating to SAD insertion and maintenance were analysed in the remaining 26 patients in the c-LMA group, 27 patients in the p-LMA group and 27 patients in the i-gel group. The flow diagram according to CONSORT guidelines ${ }^{(8)}$ is provided as Figure 1 . The characteristics of patients and surgery are presented in Table I.

Airway characteristics were similar except for upper lip biting result $(p=0.002)$. The post-hoc test to deter-

Table I. Characteristics of patients and procedures

\begin{tabular}{|c|c|c|c|c|}
\hline & Group C [n=26] & Group P [n=27] & Group I [n=27] & $\mathbf{p}$ \\
\hline Age [year] & $75.5 \pm 6.9$ & $73.1 \pm 6.5$ & $71.9 \pm 6.3$ & 0.335 \\
\hline $\mathrm{BMI}\left[\mathrm{kg} \mathrm{m}^{-2}\right]$ & $25.6 \pm 3.2$ & $27.0 \pm 2.7$ & $27.0 \pm 5.0$ & 0.209 \\
\hline Duration of anesthesia [min] & $60.0(55.0 ; 75.0)$ & $62.0(55.0 ; 75.0)$ & $60.0(50.0 ; 70.0)$ & 0.363 \\
\hline Duration of surgery [min] & $50.0(45.0 ; 65.0)$ & $50.0(45.0 ; 65.0)$ & $50.0(45.0 ; 65.0)$ & 0.553 \\
\hline Gender & & & & $0.572^{+}$ \\
\hline Male/Female & $23 / 3$ & $21 / 6$ & $24 / 3$ & \\
\hline Type of surgery & & & & $0.749^{*}$ \\
\hline Urology/Orthopedics & $18 / 8$ & $21 / 6$ & $19 / 8$ & \\
\hline ASA classification & & & & $0.503^{+}$ \\
\hline ASA $1 / 2 / 3$ & $1 / 17 / 8$ & $1 / 19 / 7$ & $3 / 13 / 11$ & \\
\hline
\end{tabular}

${ }^{*}$ Pearson Chi-Square test ${ }^{\dagger}$ Fisher-Freeman-Halton test results

Values are expressed as mean sd, median [min; max] or frequency (\%)

ASA: American Society of Anesthesiologists

Table II. Airway characteristics of patients

\begin{tabular}{|c|c|c|c|c|}
\hline & Group C [n=26] & Group P [n=27] & Group I [n=27] & $\mathbf{p}$ \\
\hline Neck circumference $[\mathrm{cm}]$ & $41.1 \pm 3.8$ & $41.2 \pm 3.6$ & $42.9 \pm 4.3$ & 0.190 \\
\hline Inter-incisor distance $[\mathrm{cm}]$ & $5.0(3.0 ; 6.0)$ & $4.0(4.0 ; 6.0)$ & $5.0(3.0 ; 6.0)$ & 0.831 \\
\hline Thyromental distance $[\mathrm{cm}]$ & $8.0(5.0 ; 11.0)$ & $8.0(7.0 ; 10)$ & $8.0(5.0 ; 11.0)$ & 0.417 \\
\hline Beard & $7(26.9)$ & $4(14.8)$ & $4(14.8)$ & $0.430^{*}$ \\
\hline Upper lip bite test & & & & $0.002^{*}$ \\
\hline Grade I-II & $26(100.0)$ & $17(63.0)$ & $17(63.0)$ & \\
\hline Grade III & $0(0.0)$ & $10(37.0)$ & $10(37.0)$ & \\
\hline Mallampati Score & & & & $0.067^{+}$ \\
\hline 1 & $7(26.9)$ & $12(44.4)$ & $8(29.6)$ & \\
\hline 2 & $19(73.1)$ & 14 (51.9) & 14 (51.9) & \\
\hline 3 & $0(0.0)$ & $1(3.7)$ & $5(18.5)$ & \\
\hline Dental status & & & & $0.822^{*}$ \\
\hline Toothed/Edentulous & $19 / 7$ & $19 / 8$ & $21 / 6$ & \\
\hline
\end{tabular}

"Pearson Chi-Square, ${ }^{\dagger}$ Fisher-Freeman-Halton test results

Values are expressed as mean sd, median [min; max] or frequency (\%)

Table III. Characteristics of successful airway insertion

\begin{tabular}{|c|c|c|c|c|}
\hline & Group C [n=26] & Group P [n=27] & Group I [n=27] & $\mathbf{p}$ \\
\hline Average insertion time [sec] & $20.0(12 ; 100)$ & $23.0(14 ; 50)$ & $25.0(13 ; 120)$ & 0.564 \\
\hline Cuff pressure [mmHg] & $20.0(0 ; 60)$ & $20.0(0 ; 65)$ & - & 0.963 \\
\hline Peak inspirator pressure [mmHg] & $15.0(8 ; 30)$ & $14.0(11 ; 25)$ & $13.0(10 ; 33)$ & 0.172 \\
\hline Plato pressure [mmHg] & $12.0(8 ; 21)$ & $12.0(7 ; 22)$ & $13.0(8 ; 32)$ & 0.260 \\
\hline Oropharyngeal sealing pressure $\left[\mathrm{cmH}_{2} \mathrm{O}\right]$ & $22.5(12 ; 40)$ & $26.0(10 ; 40)$ & $30.0(15 ; 40)$ & 0.852 \\
\hline Leak volume $[\mathrm{mL}]$ & $24.5(0 ; 91)$ & $17.0(0 ; 65)$ & $6.0(0 ; 32)$ & $0.042^{\#}$ \\
\hline Leak fraction & $0.50(0.00 ; 0.15)$ & $0.03(0.00 ; 0.13)$ & $0.01(0.00 ; 0.06)$ & $0.020^{!}$ \\
\hline Successful insertion & & & & $0.437^{+}$ \\
\hline First attempt & $21(80.8)$ & $25(92.6)$ & $23(85.2)$ & \\
\hline Second-third attempt & $5(19.2)$ & $2(7.4)$ & $4(14.8)$ & \\
\hline
\end{tabular}

"There was a significant difference between i-gel and c-LMA groups

'There was a significant difference between i-gel and c-LMA groups

Values are expressed as median [min; $\max$ ] or frequency (\%)

${ }^{+}$Fisher-Freeman-Halton test results 
Table IV. Patients' haemodynamic response to supraglottic airway insertion

\begin{tabular}{lcccc}
\hline & Group C [n=26] & Group P [n=27] & Group I [n=27] & $\mathbf{p}$ \\
\hline Mean arterial pressure [mmHg] & & & & \\
Before induction & $104.5(73.0 ; 131)^{\mathrm{a}}$ & $104.0(73.0 ; 131)^{\mathrm{a}}$ & $104.0(73.0 ; 125)^{\mathrm{a}}$ & 0.845 \\
Just after induction & $79.6(67.0 ; 121.0)^{\mathrm{b}}$ & $76.0(62.0 ; 116.0)^{\mathrm{b}}$ & $82.0(62.0 ; 121.0)^{\mathrm{b}}$ & 0.647 \\
1 min after insertion & $77.5(64.0 ; 108.0)^{\mathrm{b}}$ & $79.0(64.0 ; 120.0)^{\mathrm{b}}$ & $85.0(64.0 ; 120.0)^{\mathrm{b}}$ & 0.547 \\
3 min after inertions & $80.5(61.0 ; 99.0)^{\mathrm{b}}$ & $78.0(61.0 ; 103.0)^{\mathrm{b}}$ & $82.0(61.0 ; 103.0)^{\mathrm{b}}$ & 0.620 \\
5 min after inertions & $75.5(56.0 ; 96.0)^{\mathrm{b}}$ & $76.0(56.0 ; 97.0)^{\mathrm{b}}$ & $75.0(56.0 ; 97.0)^{\mathrm{b}}$ & 0.957 \\
$\mathrm{p}$ & $<0.001$ & $<0.001$ & $<0.001$ & \\
Heart rate [beat/min] & & & & \\
Before induction & $76.5(52.0 ; 101.0)^{\mathrm{b}}$ & $81.0(52.0 ; 108.0)^{\mathrm{b}}$ & $79.0(64.0 ; 108.0)^{\mathrm{b}}$ & 0.634 \\
Just after induction & $72.0(50.0 ; 102.0)^{\mathrm{b}}$ & $72.0(50.0 ; 107.0)^{\mathrm{b}}$ & $74.0(62.0 ; 107.0)^{\mathrm{b}, \mathrm{c}}$ & 0.579 \\
1 min after insertion & $72.5(49.0 ; 96.0)^{\mathrm{b}, \mathrm{c}}$ & $74.0(49.0 ; 107.0)^{\mathrm{b}, \mathrm{c}}$ & $75.0(58.0 ; 107.0)^{\mathrm{b}, \mathrm{c}}$ & 0.350 \\
3 min after insertion & $67.5(49.0 ; 98.0)^{\mathrm{c}}$ & $68.0(49.0 ; 98.0)^{\mathrm{c}}$ & $70.0(57.0 ; 98.0)^{\mathrm{c}}$ & 0.391 \\
5 min after insertion & $67.0(46.0 ; 96.0)^{\mathrm{a}, \mathrm{c}}$ & $67.0(46.0 ; 96.0)^{\mathrm{a}, \mathrm{c}}$ & $69.0(49.0 ; 96.0)^{\mathrm{a}, \mathrm{c}}$ & 0.382 \\
$\mathrm{p}$ & $<0.001$ & $<0.001$ & $<0.001$ &
\end{tabular}

Values are expressed as median [min; max]

$a, b, c$ The different letters indicate significantly different time points within groups $(p<0.05)$

Table V. Comparison of postoperative period parameters between the groups.

\begin{tabular}{lcccc}
\hline & $\begin{array}{c}\text { Group C } \\
{[\mathbf{n}=26]}\end{array}$ & $\begin{array}{c}\text { Group P } \\
{[\mathbf{n}=27]}\end{array}$ & $\begin{array}{c}\text { Group I } \\
{[\mathbf{n = 2 7 ]}}\end{array}$ & $\mathbf{p}$ \\
\hline Hypoxia [SpO $2<90 \%]$ & $3(11.5)$ & $2(7.4)$ & $2(7.4)$ & $0.662^{+}$ \\
Blood-stained SAD & $0(0.0)$ & $3(11.1)$ & $0(0.0)$ & $0.103^{+}$ \\
Sore throat & $0(0.0)$ & $2(7.4)$ & $0(0.0)$ & $0.325^{+}$ \\
\end{tabular}

${ }^{\dagger}$ Fisher-Freeman-Halton test result

Values are expressed as frequency (\%)

mine the group causing the difference was found to be caused by Group C ( $\left.\chi^{2}=0.000 ; p=1.000\right)$.

Outcome data for insertion are shown in Table III. While mean PIPs were similar in c-LMA, p-LMA and i-gel groups immediately just after insertion $(15,14$, $13 \mathrm{~cm} \mathrm{H} \mathrm{O}, \mathrm{p}=0172$, respectively), three patients in each group showed PIPs higher than $15 \mathrm{cmH}_{2} \mathrm{O}$.

Although oropharyngeal sealing pressure was similar among the groups $(p=0.852)$, the leak volume and leak fraction were significantly higher in the c-LMA group compared with the i-gel group (24.5 vs $6 \mathrm{~mL}$ of leak volume respectively, $p=0.042$; and 0.5 vs 0.01 of leak fraction respectively, $p=0.020$ ). While average insertion time values were similar between the groups $(p=0.564)$, the insertion time was shorter in the c-LMA group compared to p-LMA and i-gel groups (20, 23, $25 \mathrm{sec}$ respectively). Although there was a trend for a higher rate of successful insertion at first attempt with the p-LMA compared with the c-LMA and i-gel, the results were not statistically significant $(p=0.437)$. In the $c-L M A$ group, 2 patients, in the $\mathrm{i}$-gel group, 2 patients, at $3^{\text {rd }}$ attempt; in the c-LMA group, 3 patients, in the p-LMA group, 2 patients, in the i-gel group, 2 patients, at $2^{\text {nd }}$ attempt; all SADs were successfully inserted.

Comparing the heart rate and arterial pressure values between the devices, the obtained values were not different in the groups ( $p>0.05$, Table IV).

Blood-stained SADs count were significantly higher in group $P$ than the others $(p=0.034)$. As a result of post-hoc test for blood-stained SAD, no significant difference was found between the groups $(p=0.103)$. During anesthetic emergence, there were 3 cases of desaturation in group C, 2 cases in group $P$, and 2 cases in group I; because of transient breath holding that lasting less than $30 \mathrm{sec}$. Respiratory problem is solved without the need for invasive airway management ( $p>0.05$, Table $\mathrm{V})$.

\section{DISCUSSION}

Our study findings show that airway sealing pressure achieved with these devices were similar, while there was a statistically significant difference between i-gel and c-LMA groups for leak volume and leak fraction. All devices had good success rates on insertion at the first attempt in the elderly with comparable insertion times.

Most important determinant of safety and efficacy of any supraglottic airway device is considered to be OSP ${ }^{(9)}$. During positive pressure ventilation, high 
sealing pressures allow ventilation without any air leak and gastric insufflation ${ }^{(10)}$. A previous study that compared the clinical efficacy of the c-LMA in young and old adults found that the incidence of inadequate ventilation needing adjustment of airway device was higher in elderly, and authors therefore concluded that c-LMA was less effective in this age group ${ }^{(5,9)}$. In our study, although the difference was not statistically significant, we found that OSP was lower in c-LMA than $\mathrm{p}$-LMA and $\mathrm{i}$-gel in geriatric patients. C-LMA, compared to i-gel which is made of gel like thermoplastic elastomer, has a predetermined shape. Lack of adaptation of c-LMA to agerelated changes may be related to this difference. Proseal LMA has several design advantages. The dorsal cuff of p-LMA pushes the mask anterior to provide a better seal around the periglottic tissues and the drainage tube allows passively regurgitated gastric fluid to drain away from the airway ${ }^{(11)}$. A metaanalysis comparing the clinical performance of p-LMA and i-gel concluded that p-LMA provided higher OSP than i-gel. However, in the subgroup evaluation of this meta-analysis, studies using only muscle relaxants found that OSP was significantly higher in P-LMA than in i-gel. In addition, while the studies included in this meta-analysis covered a wide range of age groups from 18 to 80 years, none of them considered the influence of patient characteristics ${ }^{(12)}$. It is known that OSP may be affected by a variety of factors, such as cuff pressure, leak detection method, and age releated anatomic changes ${ }^{(13)}$. In our study, we did not use neuromusculer blocking (NMB) agent and swelling of the cuff of p-LMA may have caused malposition in these geriatric population. In a study that compares the clinical performance of i-gel and LMA supreme (sLMA) in elderly, authors found that OSP was higher in i-gel than sLMA both immediately after placement and at the end of the operation ${ }^{(13)}$. Similarly, in our study, we found that the OSP measured in the i-gel group was higher than other SADs immediately after insertion. Another noteworthy finding in this study is that leak volume and leak fraction are higher in the C-LMA group than the i-gel group. However, we think that this level of statistical difference may have a minimal effect on clinical outcomes.

With aging, chest wall compliance decreases due to structural changes of intercostal muscles, and rib spine joint ${ }^{(13)}$. Therefore, higher airway pressures may be required for adequate ventilation. The OSP should be higher than PIP for adequate ventilation with SADs. The higher the difference, the higher the possibility of providing adequate ventilation to patients requiring high inspiratory pressure is. It is clear that this will reduce the risk of gastric insufflation ${ }^{(14)}$. It should be noted that diseases of the gastrointestinal tract are more common in the elderly which makes them more susceptible to the risk of aspiration during positive pressure ventilation in the presence of concomitant diseases, such as diabetes mellitus and cognitive issues ${ }^{(6)}$. In a study, Bouvet et al. ${ }^{(14)}$ found that if PIP is lower than $15 \mathrm{cmH}_{2} \mathrm{O}$, risk of aspiration and insufflation of the stomach decreases. In our study, although the difference between OSP and PIP measured by i-gel was higher, the mean PIP measured by whole SAD was approximately 15 $\mathrm{cmH}_{2} \mathrm{O}$ and mean OSP was higher than $15 \mathrm{cmH}_{2} 0$. So, the difference between OSP and PIP was sufficient and safe for each device. There was no ventilator related problem or complication in our patients.

Reducing insertion time is more important in the elderly compared to young patients, as basal oxygen saturation is generally low, and it may be difficult to obtain adequate preoxygenation. Therefore, duration of safe apnea period in elderly is short ${ }^{(13)}$. Successful first insertion attempt rate of SAD could be affected by degree of oropharyngeal relaxation. In our study, we did not use NMB agent, but according to our protocol, all SADs were inserted after the jaw was sufficiently loose as explained above ${ }^{(15)}$. In addition, decrease in pharyngeal muscle activity may have facilitated procedure in geriatric patients.

The mean insertion times for all SADs have not shown clinically significant differences in the present study. Compared to other SADs with an inflatable cuff, the i-gel has a thermoplastic elastomer cuff that does not require inflation ${ }^{(16)}$. Several previous studies showed that the i-gel has a shorter insertion time as there is no need for cuff inflation ${ }^{(17,18)}$. However, meta-analyses showed no advantages about the insertion time of the i-gel ${ }^{(13,19-21)}$. Because insertion time may be affected by the technique of insertion of device and definition of insertion time is different between the studies that may also affect the results. 
Elderly patients show variable blood pressure responses during anesthetic induction (22). Blood pressure and heart rate tend to increase due to laryngeal stimulation during airway management ${ }^{(23)}$. Therefore, in addition to personalized and careful anesthetic induction, it would be appropriate to use an airway device that requires minimal or no power to provide airway in elderly. In our study, MAP and HR after induction decreased in three groups compared to baseline in anesthesia induction. However, there was no hemodynamic change following insertion with any of SADs.

Shin et al. ${ }^{(3)}$ reported that they did not observe any hypoxic events in a study comparing clinical performance of p-LMA, c-LMA and i-gel in adults. Shorter duration of safe apnea period may cause desaturation in geriatric patients. Nevertheless, saturation was below $90 \%$ only in 3 patients in group I, 2 patients in group $\mathrm{P}$, and 2 patients in group $\mathrm{C}$, caused by transient breath holding that lasted less than 30 seconds in the present study. All of desaturation events were resolved without the need for invasive airway management and all patients recovered without any significant morbidity.

The upper lip bite test assesses mandibular range of movement. Grades I and II of the upper lip bite test (ULBT) are thought to predict easy laryngoscopy and grade III is associated with difficult laryngoscopy (24-26). We found a statistically significant difference among the groups in terms of ULBT. Neverthless, we did not intubate patients in our study, so we don't think that this difference affected our results. The upper lip bite test can be replaced with the upper lip catch test in edentulous patients ${ }^{(24)}$. The upper lip catch test was not used in this study in edentulous patients because of slightly lower predictive accuracy ${ }^{(24,27)}$.

We didn't find any statistically significant difference among the groups in terms of postoperative airway morbidity. But the p-LMA was associated with increased rates of postoperative blood staining and sore throat compared with i-gel and c-LMA. A possible reason for the higher sore throat incidence could be big dorsal and ventral cuffs of $p$-LMA ${ }^{(11)}$.

Our study has some limitations. First, we did not measure the OSP at the end of the operation. The OSP of i-gel, may have changed at the end of the operation. Second, we did not use fiberoptic bronchoscopy to assess the anatomical position of the c-LMA, p-LMA and i-gel in relation to the vocal cords. We think that these limitations could be the aims of future studies.

\section{CONCLUSION}

The results of this study showed that the airway sealing pressure achieved with these devices was similar in the elderly. Clinicians could choose either C-LMA, p-LMA or i-gel according to their clinical experiences and personal choices. Leak volume and leakage fraction provided with i-gel were found to be lower than other SADs. Although this volume is not clinically significant, it may be important in elderly patients with COPD and restrictive lung disease.

Ethics Committee Approval: University of Health Sciences, The Ethics Committe of Diskapi Yildirim Beyazit T\&R Hospital (11.06.2018-51/20)

Conflict of Interest: None

Funding: None

Informed Consent: The patients' consent were obtained

\section{REFERENCES}

1. Brimacombe J. A proposed classification system for extraglottic airway devices. Anesthesiology. 2004;101:559. https://doi.org/10.1097/00000542-200408000-00054

2. Brain Al, Verghese C, Strube PJ. The LMA 'ProSeal'--a laryngeal mask with an oesophageal vent. Br J Anaesth. 2000;84:650-4. https://doi.org/10.1093/bja/84.5.650

3. Shin WJ, Cheong YS, Yang HS, Nishiyama T. The supraglottic airway l-gel in comparison with ProSeal laryngeal mask airway and classic laryngeal mask airway in anaesthetized patients. Eur J Anaesthesiol. 2010;6:598601.

https://doi.org/10.1097/EJA.0b013e3283340a81

4. Goyal R, Shukla RN, Kumar G. Comparison of size 2 i-gel supraglottic airway with LMA-ProSeal ${ }^{\mathrm{TM}}$ and LMAClassic $^{\mathrm{TM}}$ in spontaneously breathing children undergoing elective surgery. Paediatr Anaesth. 2012;22:355-9. https://doi.org/10.1111/j.1460-9592.2011.03757.x

5. Kim EM, Kim M-S, Koo B-N, et al. Clinical efficacy of the classic laryngeal mask airway in elderly patients: a comparison with young adult patients. Korean Journal of Anesthesiology. 2015;68:568-74. https://doi.org/10.4097/kjae.2015.68.6.568

6. Johnson KN, Botros DB, Groban L, Bryan YF. Anatomic 
and physiopathologic changes affecting the airway of the elderly patient: implications for geriatric-focused airway management. Clin Interv Aging. 2015;10:192534. https://doi.org/10.2147/CIA.S93796

7. Gatward JJ, Cook TM, Seller C, et al. Evaluation of the size 4 i-gel airway in one hundred non-paralysed patients. Anaesthesia. 2008;63:1124-30. https://doi.org/10.1111/j.1365-2044.2008.05561.x

8. Schulz KF, Altman DG, Moher D. CONSORT 2010 statement: updated guidelines for reporting parallel group randomised trials. Bmj. 2010;340:332. https://doi.org/10.1136/bmj.c332

9. Kim MH, Lee JH, Choi YS, Park S, Shin S. Comparison of the laryngeal mask airway supreme and the i-gel in paralysed elderly patients: A randomised controlled trial. Eur J Anaesthesiol. 2018;35:598-604. https://doi.org/10.1097/EJA.0000000000000700

10. Yoon SW, Kang H, Choi GJ, et al. Comparison of supraglottic airway devices in laparoscopic surgeries: A network meta-analysis. J Clin Anesth. 2019;55:52-66. https://doi.org/10.1016/j.jclinane.2018.12.044

11. Brimacombe J, Keller C. The ProSeal laryngeal mask airway: A randomized, crossover study with the standard laryngeal mask airway in paralyzed, anesthetized patients. Anesthesiology. 2000;93:104-9. https://doi.org/10.1097/00000542-200007000-00019

12. Maitra S, Baidya DK, Arora MK, Bhattacharjee S, Khanna P. Laryngeal mask airway ProSeal provides higher oropharyngeal leak pressure than i-gel in adult patients under general anesthesia: a meta-analysis. J Clin Anesth. 2016;33:298-305. https://doi.org/10.1016/j.jclinane.2016.04.020

13. In CB, Cho SA, Lee SJ, Sung TY, Cho CK. Comparison of the clinical performance of airway management with the i-gel ${ }^{\circledR}$ and laryngeal mask airway SupremeTM in geriatric patients: a prospective and randomized study. Korean J Anesthesiol. 2019;72:39-46. https://doi.org/10.4097/kja.d.18.00121

14. Bouvet L, Albert ML, Augris C, et al. Real-time detection of gastric insufflation related to facemask pressure-controlled ventilation using ultrasonography of the antrum and epigastric auscultation in nonparalyzed patients: a prospective, randomized, doubleblind study. Anesthesiology. 2014;120:326-34. https://doi.org/10.1097/ALN.0000000000000094

15. Krishnappa S, Kundra P. Optimal anaesthetic depth for LMA insertion. Indian Journal of Anaesthesia. 2011;55:504-07. https://doi.org/10.4103/0019-5049.89887

16. Van Zundert TC, Brimacombe JR. Similar oropharyngeal leak pressures during anaesthesia with i-gel, LMAProSeal and LMA-Supreme Laryngeal Masks. Acta Anaesthesiol Belg. 2012;63:35-41.

17. Lee JR, Kim MS, Kim JT, et al. A randomised trial com- paring the i-gel (TM) with the LMA Classic (TM) in children. Anaesthesia. 2012;67:606-11.

https://doi.org/10.1111/j.1365-2044.2012.07072.x

18. Schunk D, Ritzka M, Graf B, Trabold B. A comparison of three supraglottic airway devices used by healthcare professionals during paediatric resuscitation simulation. Emerg Med J. 2013;30:754-7. https://doi.org/10.1136/emermed-2012-201570

19. Choi GJ, Kang H, Baek CW, et al. A systematic review and meta-analysis of the i-gel ${ }^{\circledR}$ vs laryngeal mask airway in children. Anaesthesia. 2014;69:1258-65. https://doi.org/10.1111/anae.12746

20. de Montblanc J, Ruscio L, Mazoit JX, Benhamou D. A systematic review and meta-analysis of the i-gel $\left({ }^{\circledR}\right)$ vs laryngeal mask airway in adults. Anaesthesia. 2014;69:1151-62. https://doi.org/10.1111/anae.12772

21. Chen X, Jiao J, Cong X, Liu L, Wu X. A comparison of the performance of the I-gel ${ }^{\mathrm{TM}}$ vs. the LMA-S ${ }^{\mathrm{TM}}$ during anesthesia: a meta-analysis of randomized controlled trials. PLoS One. 2013;8:e71910. https://doi.org/10.1371/journal.pone.0071910

22. Esler MD, Thompson JM, Kaye DM, et al. Effects of aging on the responsiveness of the human cardiac sympathetic nerves to stressors. Circulation. 1995;91:351-8. https://doi.org/10.1161/01.CIR.91.2.351

23. Habib AS, Parker JL, Maguire AM, Rowbotham DJ, Thompson JP. Effects of remifentanil and alfentanil on the cardiovascular responses to induction of anaesthesia and tracheal intubation in the elderly. Br J Anaesth. 2002;88:430-3. https://doi.org/10.1093/bja/88.3.430

24. Detsky ME, Jivraj N, Adhikari NK, et al. Will this patient be difficult to intubate?: The rational clinical examination systematic review. Jama. 2019;321:493-503. https://doi.org/10.1001/jama.2018.21413

25. Eberhart LH, Arndt C, Cierpka T, et al. The reliability and validity of the upper lip bite test compared with the Mallampati classification to predict difficult laryngoscopy: an external prospective evaluation. Anesth Analg. 2005;101:284-9.

https://doi.org/10.1213/01.ANE.0000154535.33429.36

26. Khan ZH, Kashfi A, Ebrahimkhani E. A comparison of the upper lip bite test (a simple new technique) with modified Mallampati classification in predicting difficulty in endotracheal intubation: a prospective blinded study. Anesth Analg. 2003;96:595-9. https://doi.org/10.1213/00000539-200302000-00053

27. Khan ZH, Arbabi S, Yekaninejad MS, Khan RH. Application of the upper lip catch test for airway evaluation in edentulous patients: An observational study. Saudi Journal of Anaesthesia. 2014;8:73-7. https://doi.org/10.4103/1658-354X.125942 